\title{
Mixed germ cell tumour of ovary presenting as pregnancy: a rare presentation
}

\author{
Kavita Mahadevappa $^{1}$, Naveen Prasanna ${ }^{1}$, Shobha Bembalgi ${ }^{1}$, Sujata Giriyan ${ }^{2}$
}

\author{
${ }^{1}$ Department of Obstetrics \& Gynaecology, Karnataka Institute of Medical Sciences, Hubli, Karnataka - 580021, India \\ ${ }^{2}$ Department of Pathology, Karnataka Institute of Medical Sciences, Hubli, Karnataka - 580021, India
}

Received: 25 September 2015

Accepted: 02 November 2015

\section{*Correspondence:}

Dr. Kavita Mahadevappa,

E-mail: kavipgi10@gmail.com

Copyright: (C) the author(s), publisher and licensee Medip Academy. This is an open-access article distributed under the terms of the Creative Commons Attribution Non-Commercial License, which permits unrestricted non-commercial use, distribution, and reproduction in any medium, provided the original work is properly cited.

\begin{abstract}
Malignant mixed germ cell tumour of the ovary containing embryonal carcinoma and choriocarcinoma is a very rare entity. These tumours can present as precocious puberty or menstrual irregularities in adolescent girls. Here we report a case of 22 year old lady who presented as 5 months pregnancy in antenatal clinic. MRI Imaging and tumour markers revealed malignant ovarian tumour. Patient underwent surgicopathological staging and was found to have malignant mixed germ cell tumour stage IIIB, comprising of both choriocarcinoma and embryonal carcinoma components. Patient received one cycle of chemotherapy and was called for follow up. Mixed malignant germ cell tumour of the ovary is a highly aggressive neoplasm that can present in advanced stage. A high clinical suspicion is needed in patients presenting with pelvic mass associated with menstrual irregularity or amenorrhoea in adolescent and young women.
\end{abstract}

Keywords: Mixed germ cell, Pregnancy, Young women, Choriocarcinoma, Embryonal carcinoma

\section{INTRODUCTION}

Germ cell tumour constitutes $20-25 \%$ of all ovarian neoplasms. Among them $3 \%$ are malignant in western countries. ${ }^{1,2}$ In asian countries they constitute $15 \%$ of all ovarian tumours. Below the age of $20 \mathrm{yrs}, 70 \%$ of ovarian tumours are germ cell origin (one third are malignant). It is a tumour which grows rapidly, characterized by subacute pelvic pain. The growing tumour may produce bowel and bladder disturbances and menstrual irregularities. Mixed germ cell tumours are rare germ cell tumours. A mixture of dysgerminoma and endodermal sinus tumour is the most common combination accounting for one third of mixed germ cell tumours3. Combination of embryonal carcinoma and choriocarcinoma is very rare. Here we are presenting a case of mixed germ cell tumour comprising of choriocarcinoma and endodermal carcinoma, which presented as pregnancy.

\section{CASE REPORT}

A 22 yrs old G2P1L1 presented in antenatal out patient department with 5 months amenorrhoea with polyhydramnios on 18th June 2015 to KIMS, Hubli. Urine pregnancy test was positive at 3rd month of pregnancy. H/o excessive vomiting was present. Quickening not felt.

On examination, patient had pallor+, exophthalmus + , stellwag's sign + , right lower limb varicose veins + and thyroid examination was normal. Her BMI was 20.4 and her vitals were normal. On palpation a midline mass corresponding to uterine size-28wks felt.. No fetal parts palpable. No fetal heart sounds heard. On vaginal examination, cervix was pushed posteriorly, uterus not made out separately, fornices full. Movements of the cervix not conducted to the abdominal mass. On rectal examination, a mass felt anteriorly, rectal mucosa free. 
Investigations revealed,

- $\quad$ USG-Large ill defined ovarian mass with solid and cystic components. Increased vascularity with low resistance waveform.

- MRI- Complex mixed intensity lesion, with solid and cystic components - Ovarian neoplasm. Uterus normal. Gut-Normal, Lymphnodes-Normal.

- Tumor markers: B-HCG = 70,440 miu/ml, Alphafetoprotein=Normal, $\mathrm{LDH}=$ Normal, $\mathrm{CA}-125=41$

- Thyroid profile- T3-14.69pg/ml, T4-3.19ng/dl, TSH-0.059 suggestive of hyperthyroidism+.

Management based on the above findings a diagnosis of Ovarian tumour - Germ cell tumor - Choriocarcinoma ?? Teratoma was made. She was taken up for exploratory laparotomy with surgical staging and optimal debulking surgery on 23rd July 2015. Intraoperatively there was right ovarian tumour of $26 \times 20 \mathrm{cms}$ and left ovarian tumour $15 \times 10 \mathrm{cms}$, both were adherent to bowel and omentum as seen in Figure 1 and 2. Tumour deposits of $<1 \mathrm{~cm}$ were present on the omentum and gut.

- Operative procedure done - Total abdominal hysterectomy and bilateral salpingoophorectomy with infracolic omentectomy.

- Histopathological examination revealed- Mixed Germ Cell Tumor with Choriocarcinoma and Embryonal carcinoma components.

- Surgicopathological Staging - Mixed germcell tumour stage IIIB.

- Patient received one cycle of BEP chemotherapy and was advised for follow up.

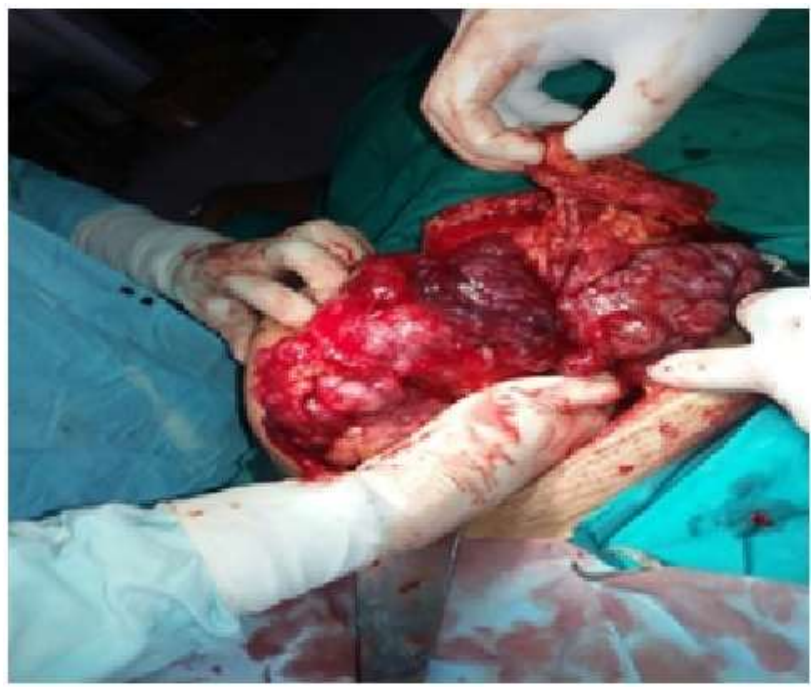

Figure 1: Intraoperative findings of ovarian tumour.

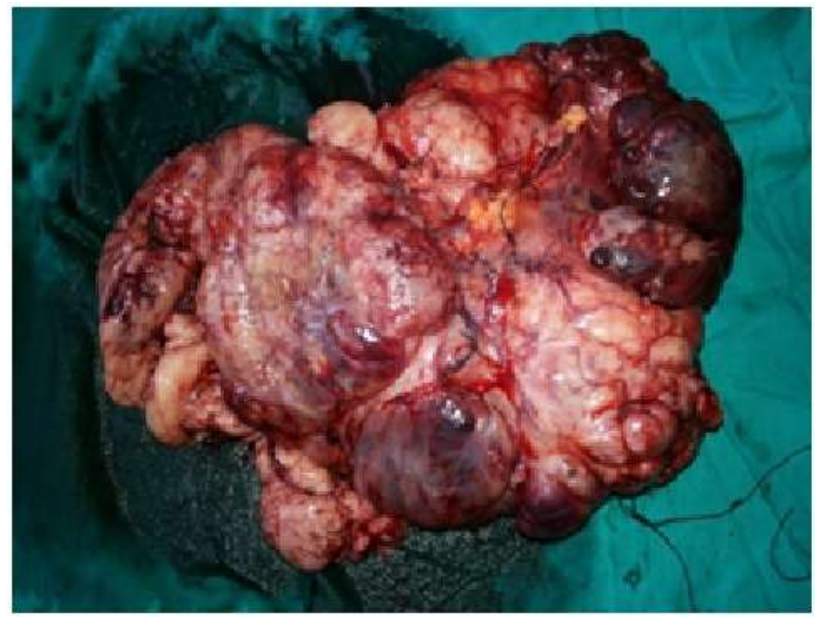

Figure 2: Specimen of ovarian tumour.

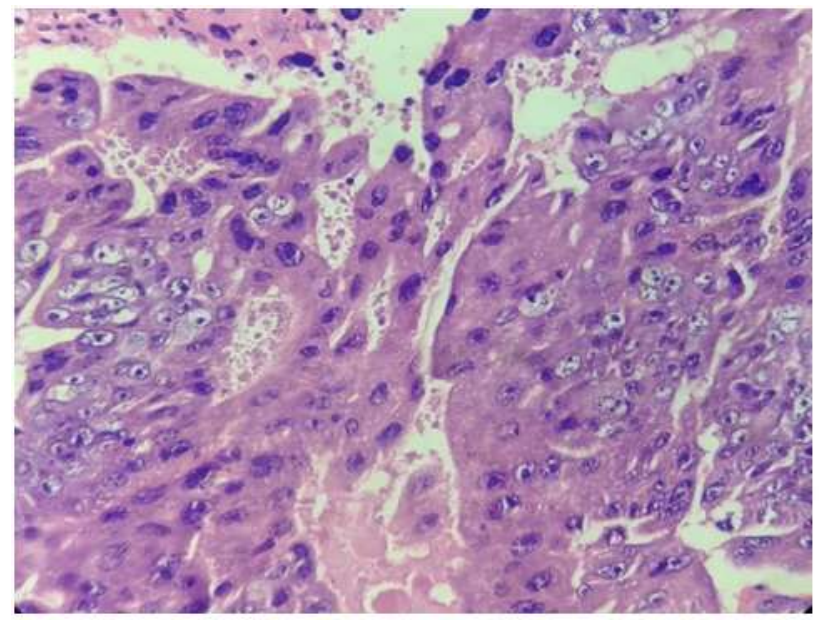

Figure 3: Photomicroscopy of ovarian tumour sections showing choriocarcinoma tumour component.

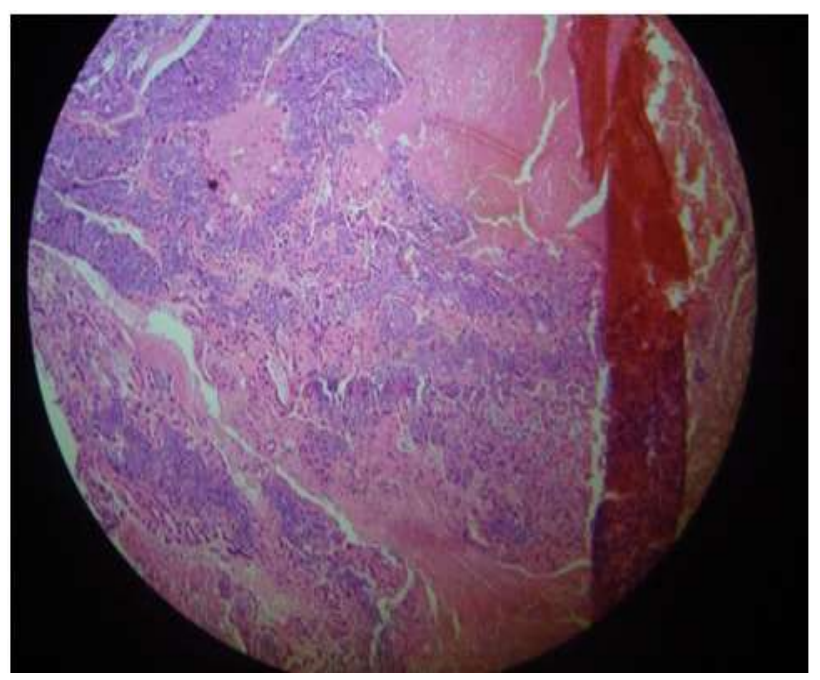

Figure 4: Photomicroscopy of choriocarcinoma of ovary showing areas of necrosis and haemorrhage. 


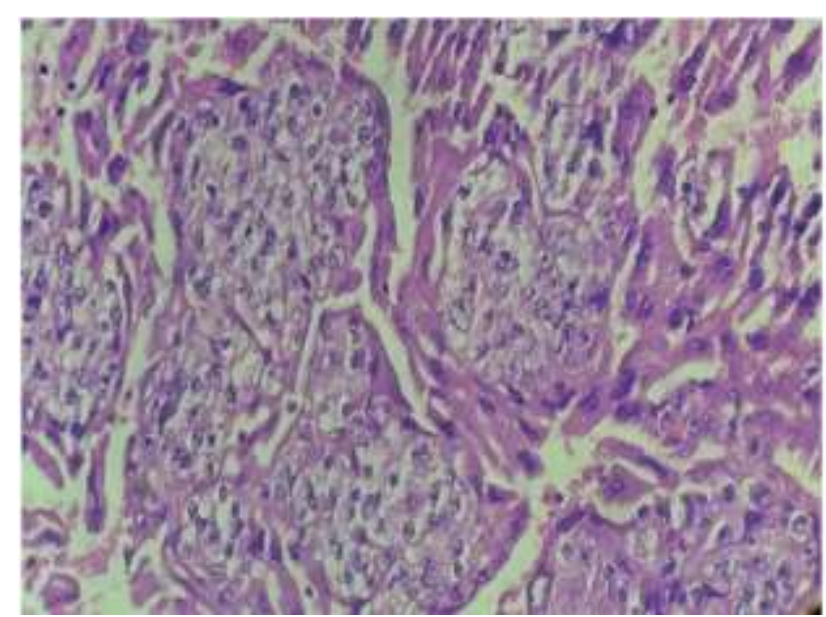

Figure 5: Photomicroscopy of ovarian tumour showing embryonal component.

\section{DISCUSSION}

Ovarian germ cell neoplasms are thought to be derived from primitive germ cell of the embryonic gonad. In 1973, WHO classified germ cell tumours as dysgerminoma, endodermal sinus tumour, embryonal carcinoma, polyembryoma, choriocarcinoma, teratoma, mixed and gonadoblastoma. ${ }^{4}$ Mixed germ cell tumours of the ovary contain two or more elements of lesions described above. In one of the series5, the most common component of mixed malignant tumour is dysgerminoma(80\%), followed by $\operatorname{EST}(70 \%)$, Immature teratoma (53\%), Choriocarcinoma (20\%) and embryonal carcinoma (16\%). The most frequent combination was a Dysgerminoma and EST. In our patient the combination was choriocarcinoma and embryonal carcinoma which is a very rare component of mixed germ cell tumour. The average age of patients with germ cell tumour is $13.8 \mathrm{yrs}$ (range, 4 to 27 years) ${ }^{6}$. The presentation includes abdominal mass, abdominal pain and fever. Average size at presentation is $15.5 \mathrm{cms}$. Germ cell tumour demonstrates variable consistency ranging from completely solid to largely cystic. The appearance of malignant germ cell tumour varies according to individual constituents, but is generally complex, predominantly solid tumour. Imaging modalities like CT scan and MRI are useful to establish a diagnosis, helpful in delineating the size and complexity of these tumours. Preoperative staging of tumour is possible with CT scan. ${ }^{7}$ Different types of germ cell tumour show overlapping radiological appearances; the definitive diagnosis is made by histological examination. In our patient MRI scan showed, complex mixed intensity lesion, with solid and cystic components suggestive of ovarian neoplasm.

The mixed lesions may secrete AFP, HCG, or both or neither of these markers, depending on the components. Embryonal carcinoma may secrete estrogen, with patient exhibiting symptoms and signs of precocious puberty or irregular vaginal bleeding. In case of non-gestational choriocarcinoma, the presence of high HCG levels causes isosexual precocity in patients whose lesions appear before menarche. In reproductive age group 8 the symptoms could resemble pregnancy with amenorrhoea and positive urine pregnancy test, as seen in our patient. Embryonal carcinoma of ovary is an extremely rare tumour and represent only $4 \%$ of malignant ovarian germ cell tumour. It is distinguished from choriocarcinoma by absence of syncytiotrophoblast and cytotrophoblast cells ${ }^{9}$. Pure non gestational choriocarcinoma of ovary is extremely rare, as it is nearly always admired with other germ cell elements. Histologically it has the same appearance as gestational choriocarcinoma which metastasize to ovary. The combination of embryonal cell carcinoma and choriocarcinoma in mixed germ cell tumour is rare, which was reported by Koshy et al. ${ }^{10}$ Our patient also showed the components of embryonal carcinoma in Figure 5, and choriocarcinoma in Figure 3 and 4 .

The treatment of early mixed germ cell tumour is primarily surgical, including resection of primary lesion and proper surgical staging. Because the disease, principally affects girls and young women, special consideration must be given to preservation of fertility and use of chemotherapy as needed whenever possible. All the patients except those with FIGO stage Ia, require combination chemotherapy, preferably bleomycin, etoposide and cisplatin (BEP) or vincristine, adriamycin and cyclophosphamide (VAC). The serum markers if positive initially may become negative during chemotherapy, but this finding may reflect regression of only a particular component of mixed lesion. Therefore imaging techniques and second look laparotomy may be indicated to determine the precise response of therapy, if macroscopic disease was present at the initiation of chemotherapy.

Important prognostic factor is the size of the primary tumour and the relative size of its most malignant component. Stage IA lesions smaller than $10 \mathrm{~cm}$ survival is $100 \%$. Tumours composed of less than one-third EST, choriocarcinoma, or grade 3 immature teratomas also have an excellent prognosis, but it is less favourable when these components constitute most of the mixed lesions. A recent retrospective study has shown that elevation of both AFP and HCG levels were a strong predictor of poor survival, based on univariate and multivariate analysis. Advanced stage disease at presentation was also an independent poor prognostic indicator. ${ }^{11}$ Our patient has a poor prognosis due to large tumour size, advanced stage at presentation, unfavourable histological type occupying more than one third of the tumour.

Malignant mixed germ cell tumour of the ovary is a rapidly growing tumour having variable presentation. A high clinical suspicion is needed in patients presenting with pelvic mass associated with menstrual irregularity or amenorrhoea in adolescent and young women. 
Funding: No funding sources

Conflict of interest: None declared

Ethical approval: Not Required

\section{REFERENCES}

1. Scully RE, Young RH, Clement PB. Tumours of the ovary, maldeveloped gonads, fallopian tube and broad ligament. In: Atlas of tumour pathology. Washington: Armed forces institute of pathology;1998.

2. Berek JS, Hacker NF. Practical gynecologic oncology, 3rd ed. Philadephia: Lippincott Williams \& Wilkins, 2000:3-38.

3. Kurman RJ, Norris HJ. Embryonal carcinoma of the ovary: A clinicopathological entity distinct from endodermal sinus tumour resembling embryonal carcinoma of adult testes. Cancer. 1976;38(6):242033.

4. Gershenson DM. Update on malignant ovarian germcell tumour. Cancer. 1993;7:1581-90.

5. Oliva E, Andrada E, Pezzica E, et al. Ovarian carinomas with choriocarcinomatous differentiation. Cancer. 1993;72:2441-46.

6. Brammer HM 3rd, Buck JL, Hayes WS, Sheth S, Tavassoli FA. From the archieves of AFIP.
Malignant germcell tumours of the ovary: radiologicpathologic correlation.Radiographics.1990;10:71524.

7. Lim FK, Chanrachakul B, Chong SM, Ratnam SS. Malignant ovarian germcell tumour: experience in national hospital of Singapore. Ann Acad Med Singapore. 1998:27(5):657-61.

8. Berek JS, Hacker NF. Practical gynecologic oncology, 5rd ed. Philadephia: Lippincott Williams \& Wilkins, 2007.

9. Berek JS, Adashi EY, Hillard PA, editors, Novaks gynaecology. 12th ed, Baltimore: Williams \& Wilkins, 1996.

10. Koshy M, Vijayananthan A, Vadiveloo V. Malignant ovarian mixed germ cell tumour: a rare combination. Biomed Imaging Interv J. 2005;1(2):e10.

11. Murugaesu N, Schmid P, Dancey G, et al. Malignant germcell ovarian tumours: identification of novel prognostic markers and long-term outcome after multimodality treatment. J Clinico Oncology. 2006;24:4862-6.

Cite this article as: Mahadevappa K, Prasanna N, Bembalgi S, Giriyan S. Mixed germ cell tumour of ovary presenting as pregnancy: a rare presentation. Int J Reprod Contracept Obstet Gynecol 2015:4:2084-7. 